\title{
قيود المقاولية في بيئة المؤسسات الصغيرة والمتوسطة
}

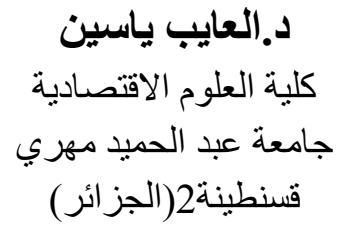

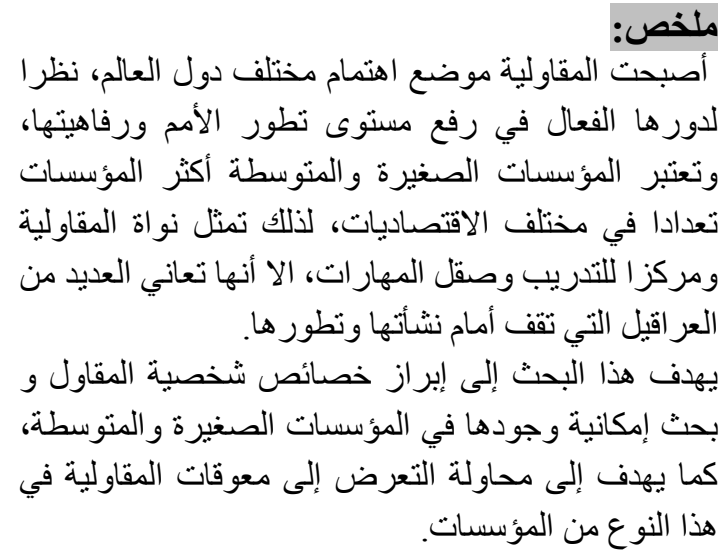

\section{Résumé:}

L'entrepreneuriat devenu au centre des occupations dans toutes les économies, en raison de son rôle dans le développement et l'aisance des nations. Les pme représentent la majorité des entreprises dans tous les pays, de ce fait, elles sont le noyau de l'entrepreneuriat, et le centre d'apprentissage et d'excellence. Malgré ça elles souffrent de multiples contraintes qui empêchent leurs créations et leurs développements.

Ce travail de recherche vise à démontrer les caractéristiques de la personnalité entrepreneuriale, et analyser la possibilité de la trouver chez les pme. Ainsi il tente de mettre en exergue les différentes contraintes de l'entrepreneuriat dans ces entreprises. 
مختلف المجالات، وما وصلت إليه الأمم من تطور إلا نتاجا لروح المبادرة والابتكار اللذان يعتبران من

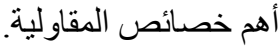

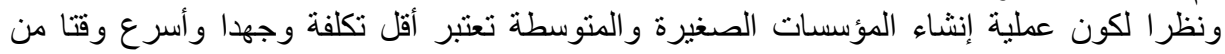

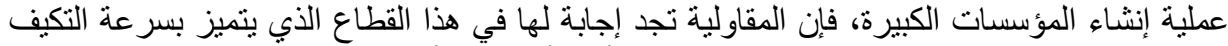

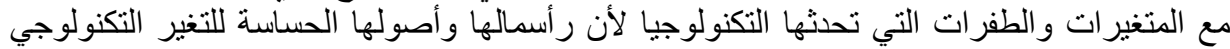

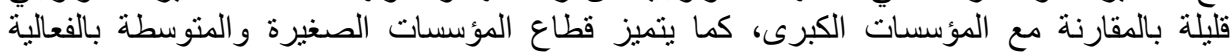

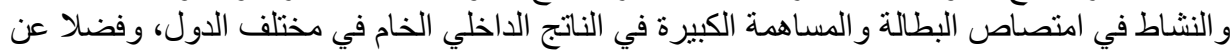

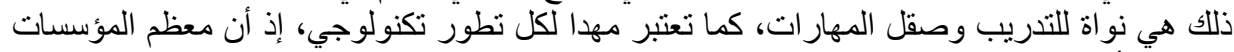
الكبيرة بدأت صغيرة.

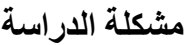
تدور مشكلة الدر اسة حول التساؤل الرئيسي التالي:

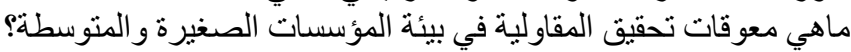

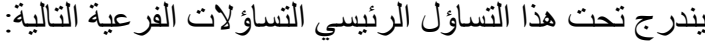

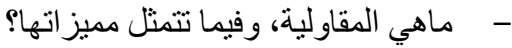

- - هل تختلف خصائص الثخصية المقاولية باختلاف حجم المؤسسات؟

- - هل العوامل المتعلقة بتحقيق الحس المقاولاتي مرتبطة بخصوصية المؤسسة الصغيرة و المتوسطة؟ أم بدو افع المسير؟ المتئ

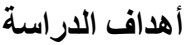

نهذف من خلال هذا البحث إلى تحديد مفهوم المقاولية وتسليط الضوء على ولى خصائص شخصية الدقاول

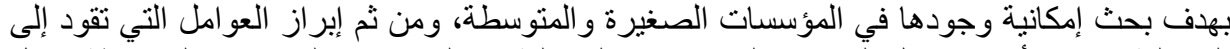

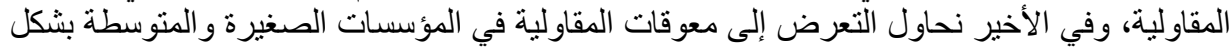
عام و المؤسسة الصغيرة و المتوسطة في الجز ائر بشكل خاص. منهجية الاراسة المانة

للإجابة على تساؤلات الدراسة وبلوغ الأهداف المرجوة، اتبعنا المنهج التاريخي في تتبع تطور التنظيم

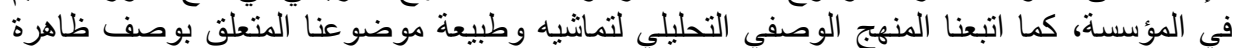

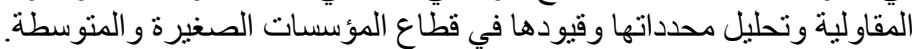

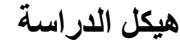

تم تقسيم الدر اسة إلى أربعة محاور، يعالج المحور الأول تطور الفكر التنظيمي في المؤسسة الاقتصادية

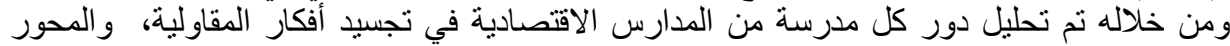

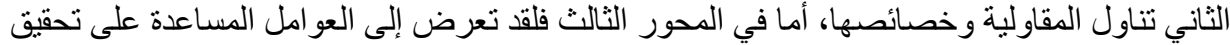

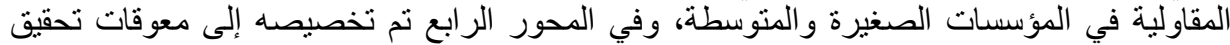
المقاولية في المؤسسات الصغيرة الصئر المنتوسطة.

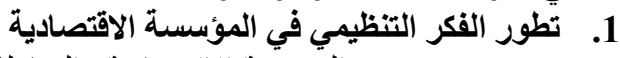

اختلف تفسير وتحديد مفهوم المؤسسة الاقتصادية و المقاولة، عبر مختلف فئلف مر احل تطور الفكر التنظيمي، وسنحاول في هذا المجال التطرق إلى مساهمة تللك الددارس في تحديد مفهوم الكؤية الكؤسة الاقتصادية:

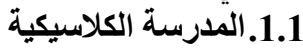

ساهمت المدرسة الكلاسيكية في تأسيس جملة من المبادئ و النظريات المتباينة حول المؤسسة الاقتصادية

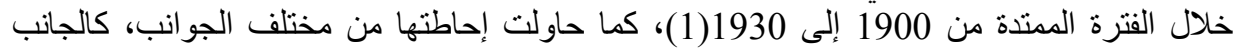

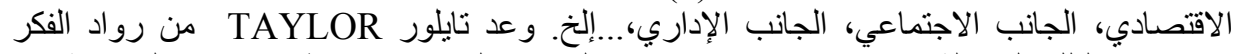

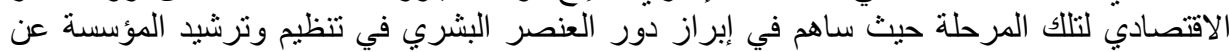
طريق التنظيم العلمي للعمل من خلال التخصص التص دور العمودي والتوزيع العلمي للعمال والأنثطة، أما 


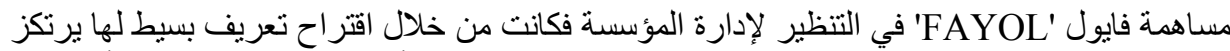

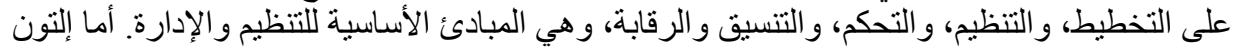

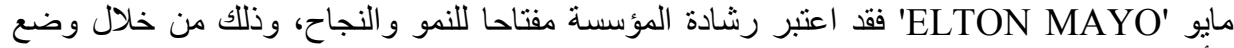

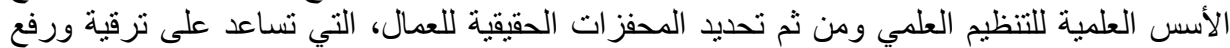
المردودية في المؤسسة، ألاو وهي تحسين العلاقات الإنسانية بداخلها.

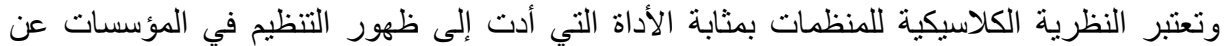

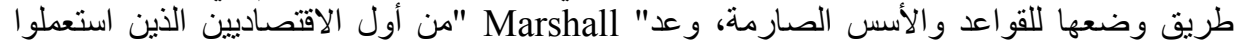

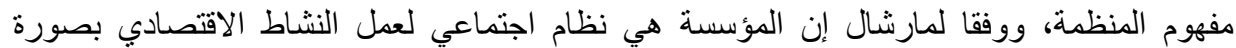

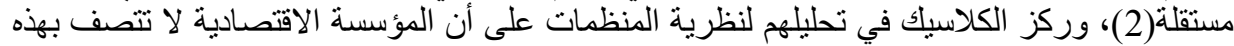

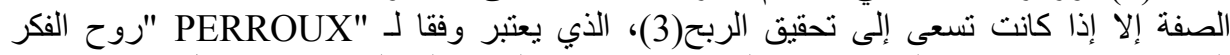

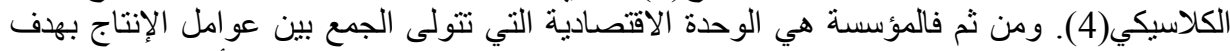

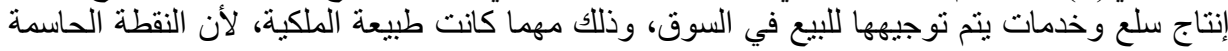

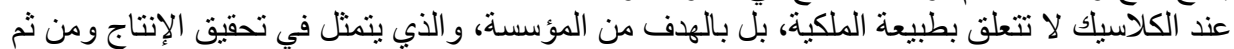

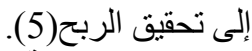

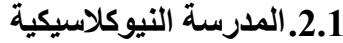

ترتكز النظرية النيوكلاسيكية للمؤسسة على أربعة ألى فريع فرضيات أساسية، وهي استقلالية الفرد، الرشادة،

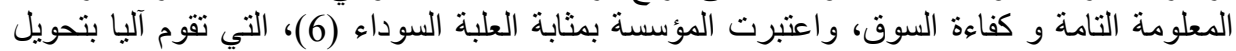

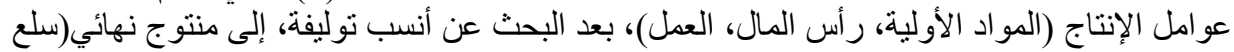

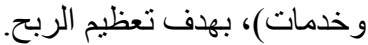
قيدت فرضيات النموذج النيوكلاسيكي التحليل الوظيفي للمؤسسة، كون النموذج لا يهنم بالتنظيم الداخلي

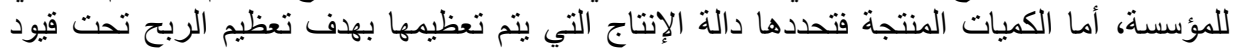

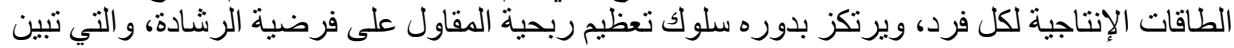

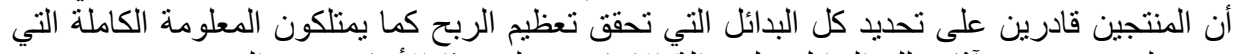

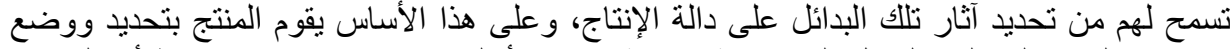

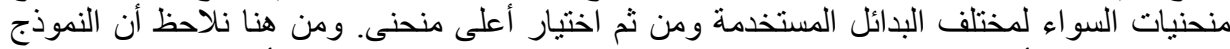

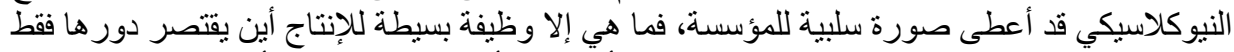

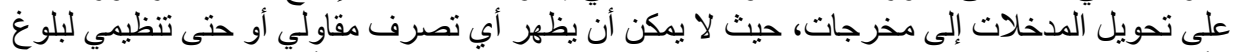

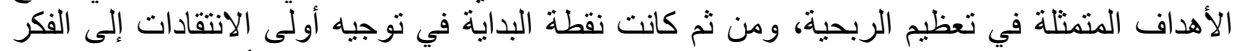

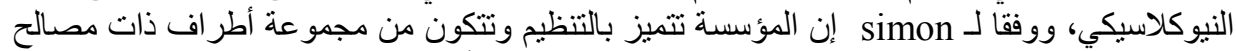

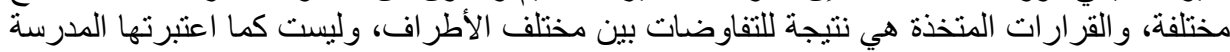

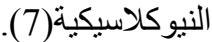

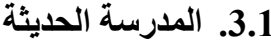

ظهرت النظرية الحديثة للمنظمات بعد الانتقادات التي وجهت إلى النظرية النيوكلاسيكية، حيث أنها تمثل

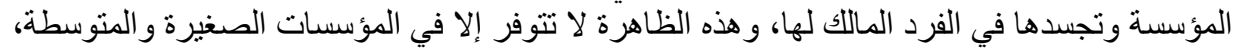

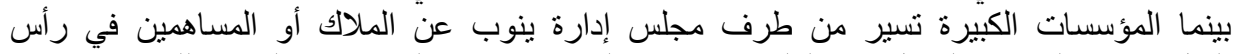

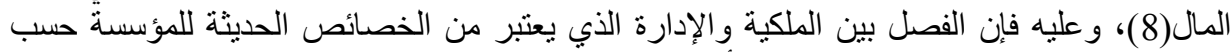

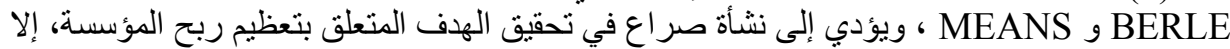

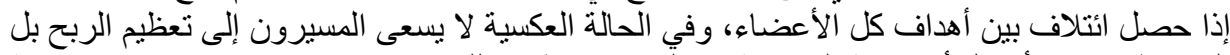

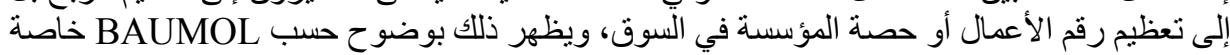

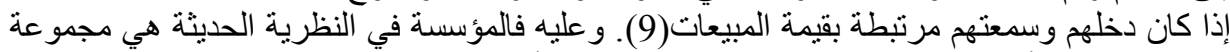
من العقود تنظم أنماط وطرق التوليف بين الدذخلات من أجل إنتاج مخرجات، ونوزيع التئ العوائد الناتجة 


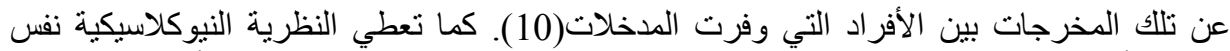

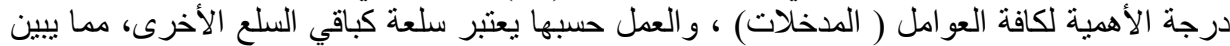

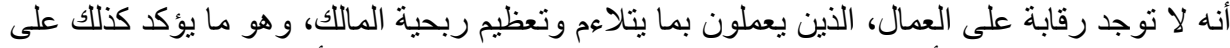

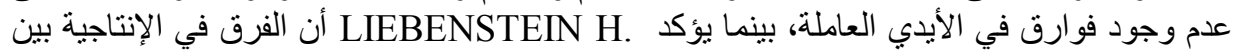

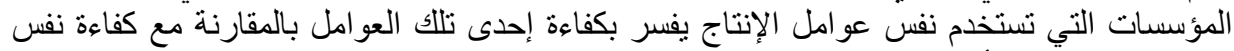

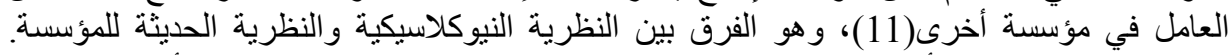

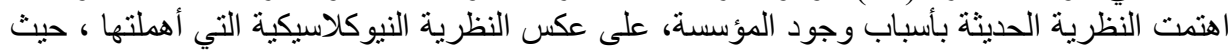

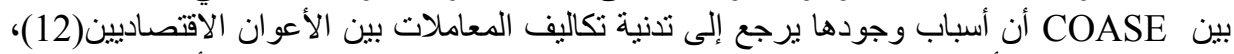

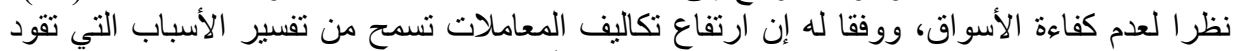

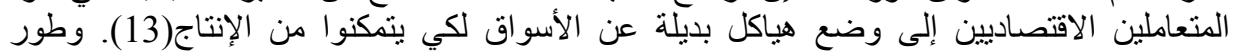
williamson

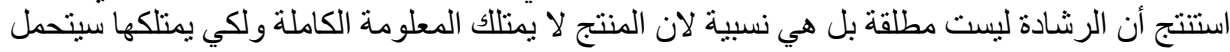

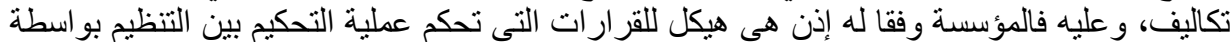

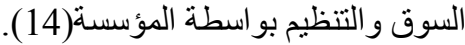

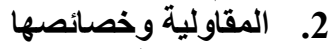

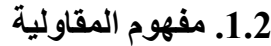

تعتبر المقاولية من المواضيع الحديثة التي أضحت تستحوذ على اهتمامات الباحثين

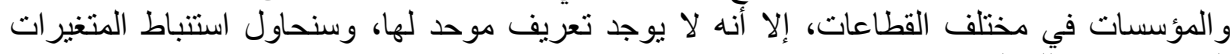
المشتركة بين تلك التعاريف.

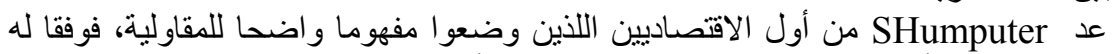

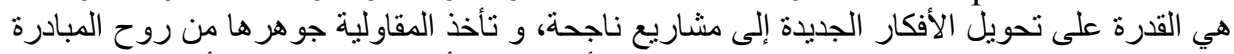

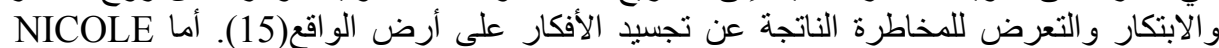
فقد وضع مفهوما للمقاولية آخذا بعين الاعتبار ثلاثة أبعاد تعكس مميزات التحات الثخصية

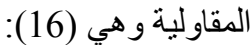

- - مبد النظر: وفقا لـ AUBERT إن المقاول يمتلاك إستر اتيجية للمثنابرة، و لا يتوقف عند الحدود

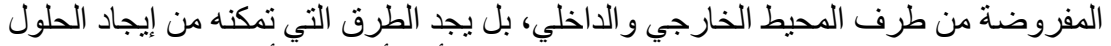

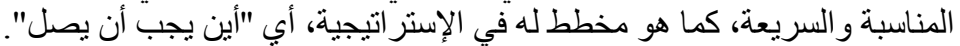

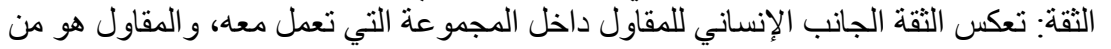

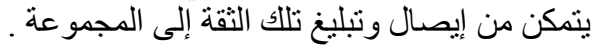

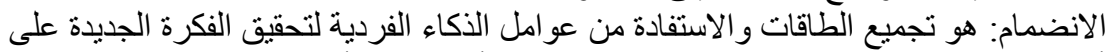

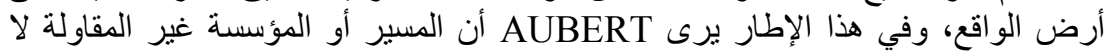

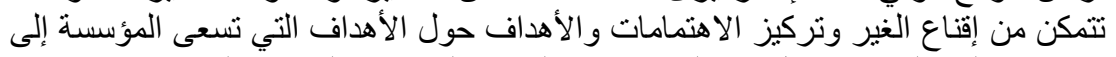

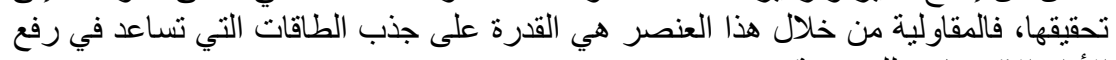

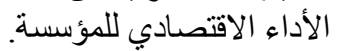

تعرف المقاولية حسب .ALLALI B. على أنها وضع رؤية جديدة ثم تعبئة كل المجهودات من أجل

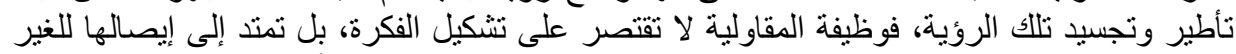

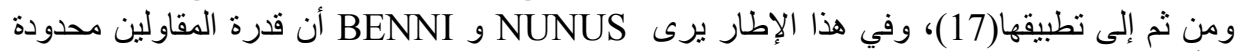

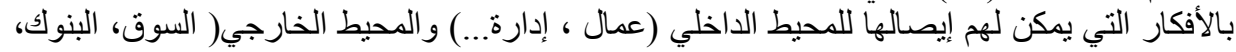

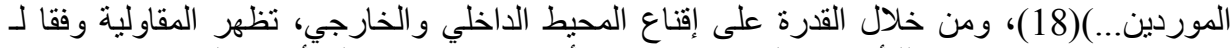

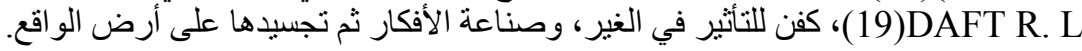


من خلال التعاريف السابقة يمكن القول أن المقاولية هي متغير تابع لعدة عو امل كالقدرة على التأثير في التئي

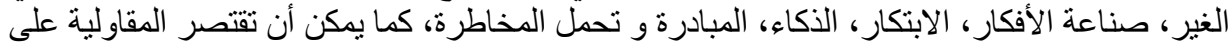

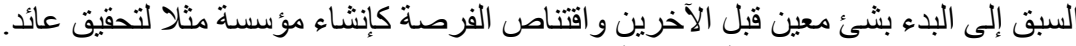

\subsection{2. خصائص الثخصية المقاولة الألة}

COLLERETTE P. ROY أجمعت العديد من الدراسات والأبحاث التطبيقية والنظرية (كدراسة التصاية

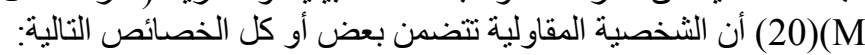

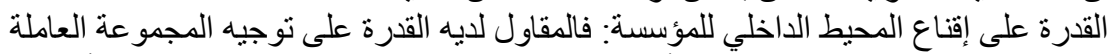

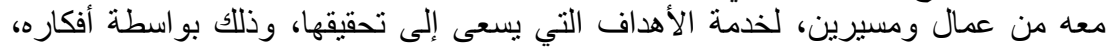

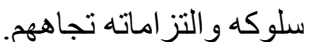
ترجمة الأهداف إلى إجراءات، تتميز الثخصية المقاولية بالتحديد الدقيق للأهداف الأساسية

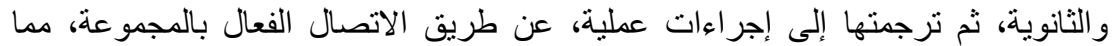

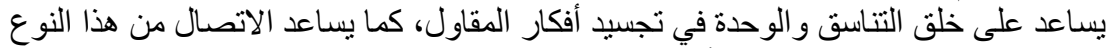

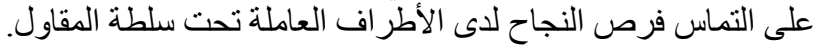

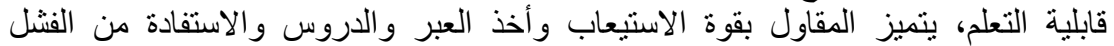

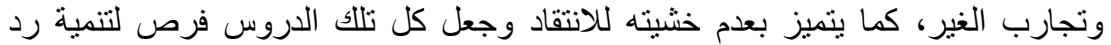

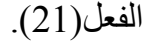

حسن الاستماع إلى الغير، إذ يقوم المقاول بالاستماع إلى كافة أعضاء المجموعة العاملة معهد

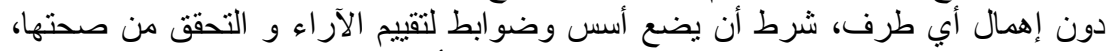

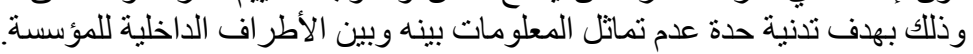

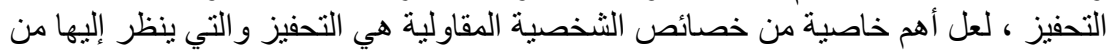

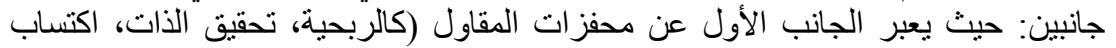

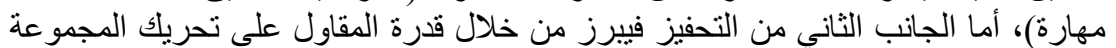

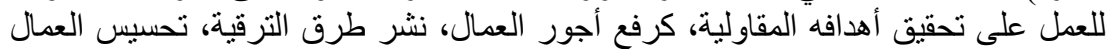
و المسيرين بالثقة و الأمان.

القدرة على التشخيص، ومن خلالها يتمكن الفرد من تحديد نقاط القوة وتعزيزها وتحديد نقاط

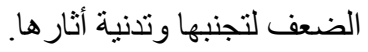

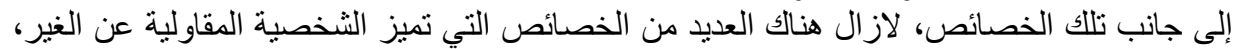

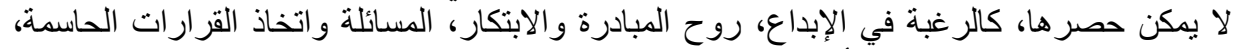

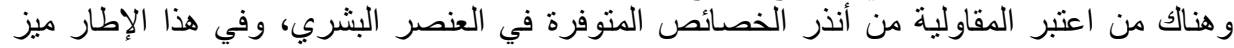
FORTIN P.A. جدول رقم 1: الفرق بين المسير و الدقاول

\begin{tabular}{|c|c|c|}
\hline 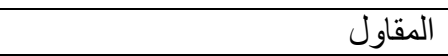 & المسير & الخصائص \\
\hline 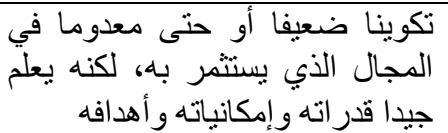 & 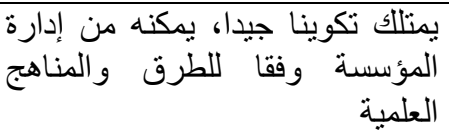 & المهارة في التسيير \\
\hline أفضضل الطرق تحمل الخطيره، و البحث عن & 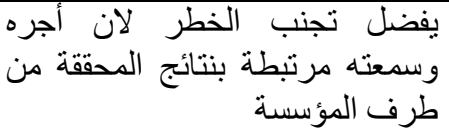 & رد الفعل تجاه الخطر \\
\hline أهم خصائصله هي الابتكار على المهول، لأن & عدم التعرض للخطر & التأكدفه من حالات عدم \\
\hline محفز بالاهداف الثخخصية & محفز بالسلطة التي يمتلكها & التحفيز ات \\
\hline
\end{tabular}


Source: FORTIN P.A., devener entrepreneur pour un Québec plus entrepreneurial, presses universitaire Laval, 1992, P65.

ما يلاحظ من خلال الجدول والخصائص السابقة أن المؤسسة الصغيرة و المتوسطة قد تتوفر على تلألك

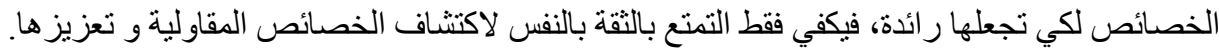

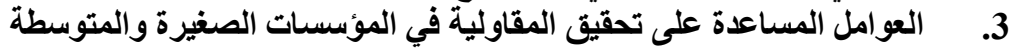

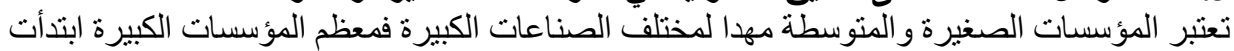

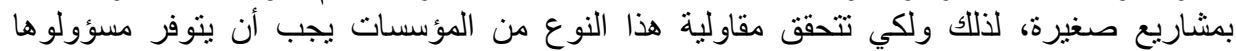

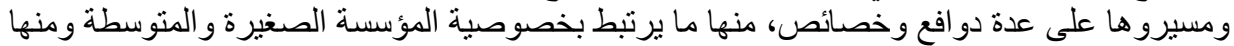
ما يرتبط بمميز ات المسير و أهدافه.

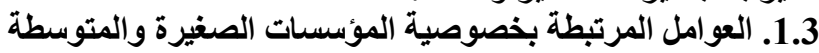

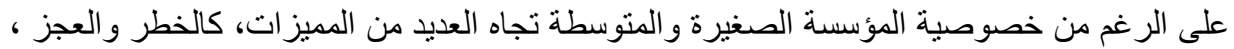

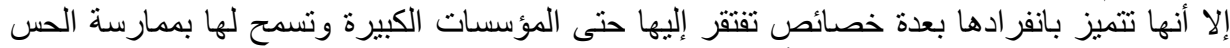

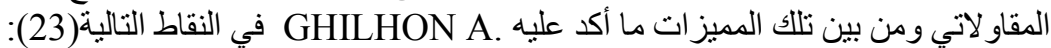
1.1.3 1.الثقافة التنظيمية الجيدة

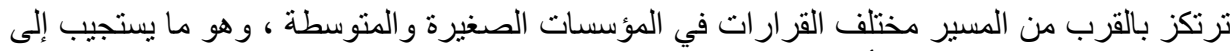

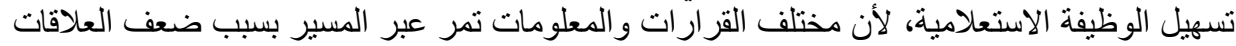

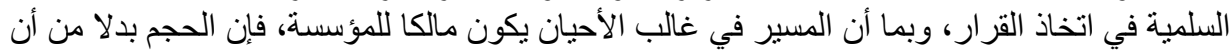

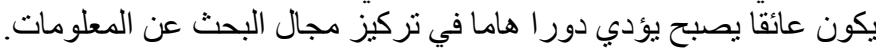
السلوك الجيد للتغيير

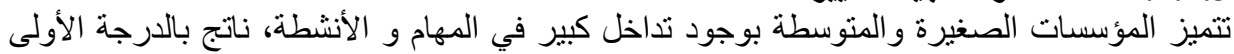

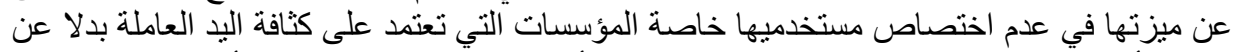

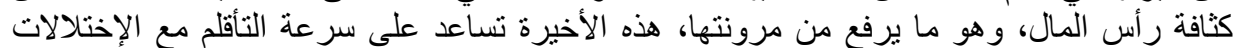

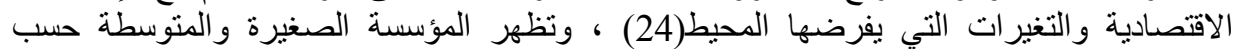

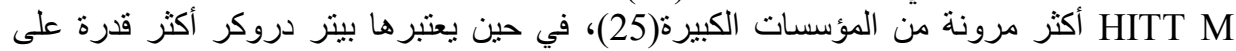

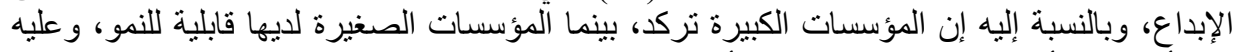

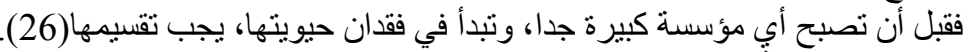

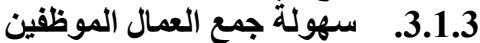

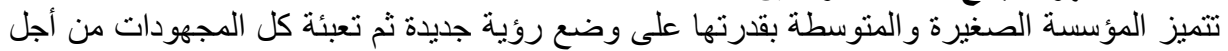

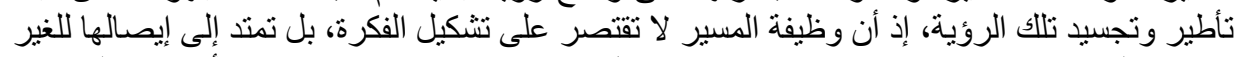

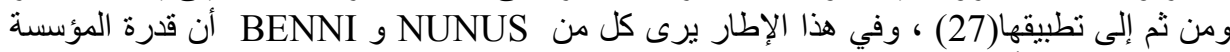

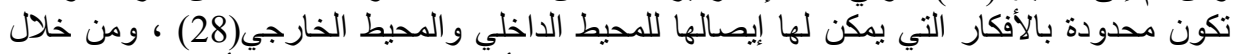

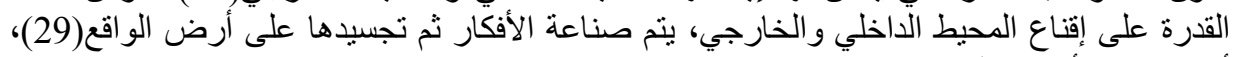
أي ترجمة الأهداف إلى إجراءات.

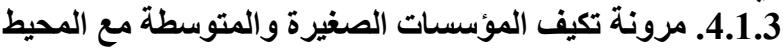

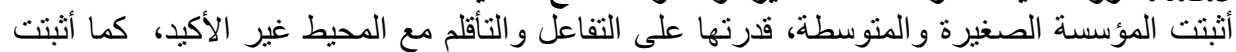

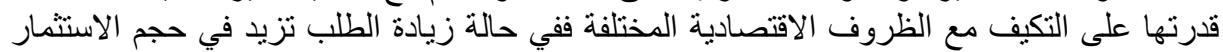

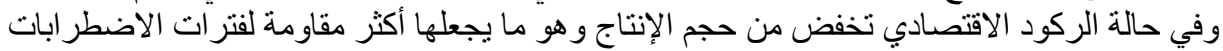

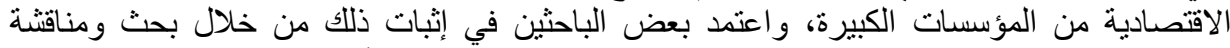

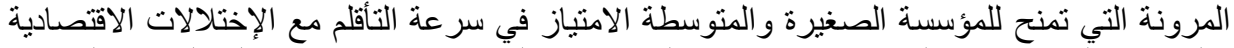

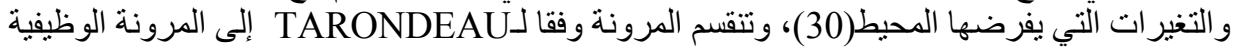
و المرونة الإستر اتيجية. 
تغطي المرونة الوظيفية قدرة المؤسسة الصغيرة و المنوسطة على تكييف مو اردها بأمثل طريقة، وتتحقق

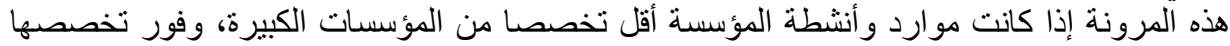

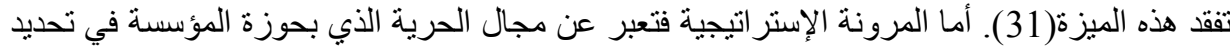

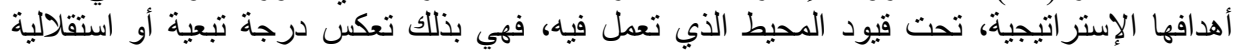

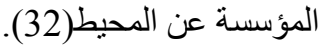

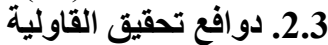

لا تختص المؤسسات الصغيرة والمتوسطة لوحدها بهذه الدوافئ الهو وإنما هي دوافع نرتبط بالثخصية

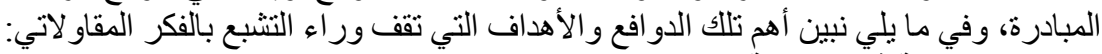

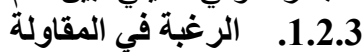

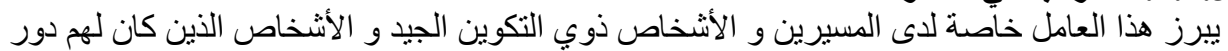

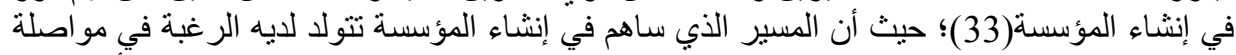

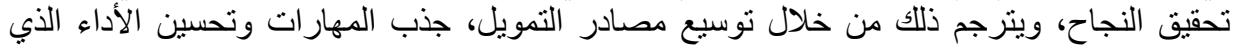

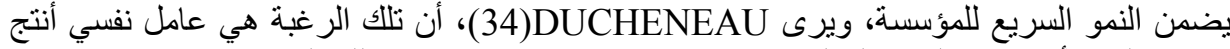

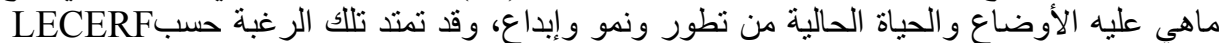
إلى درجة الاحتكار أين تصبح أهداف المؤسسة موجهة لزيادة حصنية الأها في في السوق وامتلاك أكبر نسبة

2.2.3

و MEYER F. تم دراسة هذا العامل بكثرة في الولايات المتحدة الأمريكية كدراسة العاتة ROSENMAN H.

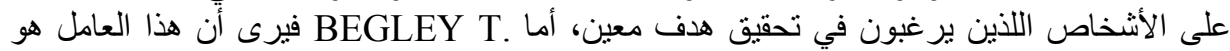

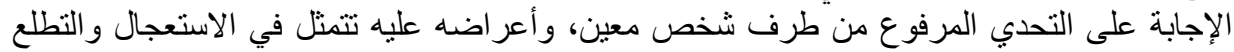

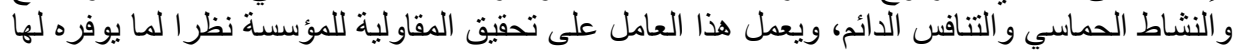

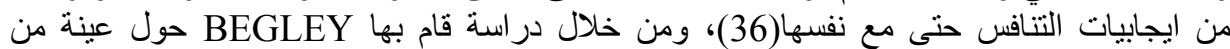

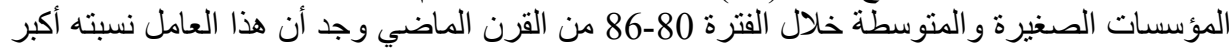

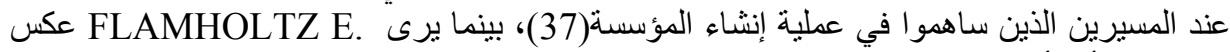

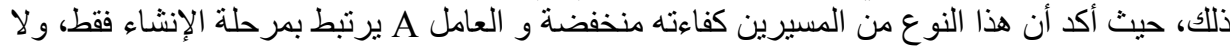

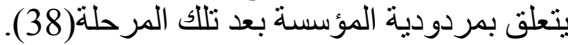

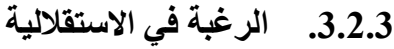

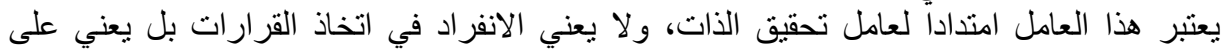

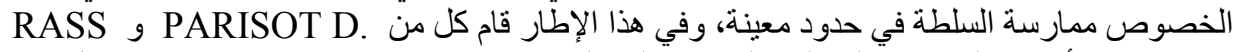

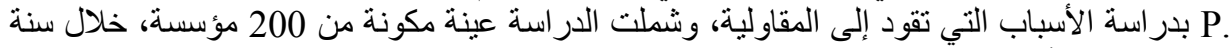

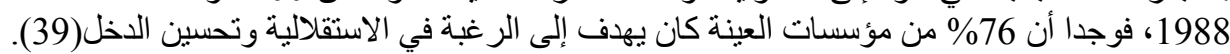

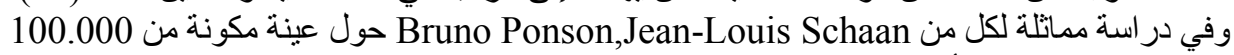

مؤسسة صغيرة، وجدا أن 15000 منهم يهذف من خلال مشرو عه إلى التمتع بروح الاستقلالية (40). (4.2.3

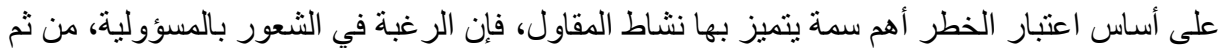

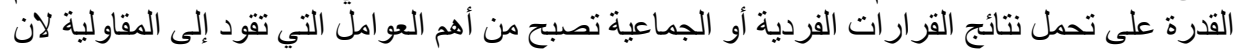

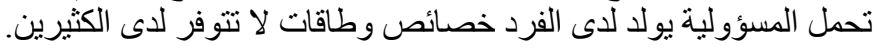
5.2.3

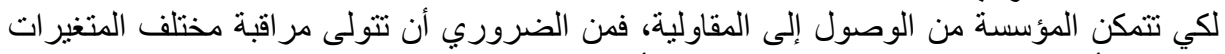

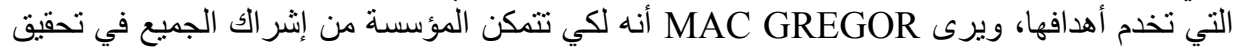
المقاولية، يجب التمييز ما بين نو عين من الرقابة، و هما: 
النوع X: يطبق هذا النوع من الرقابة على الثخص الذي لا يحب العمل، ويعمل كل ما بوسعه لتجنبه، النئه

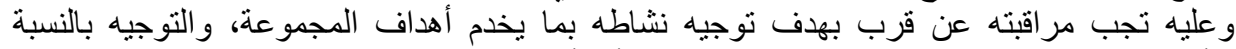

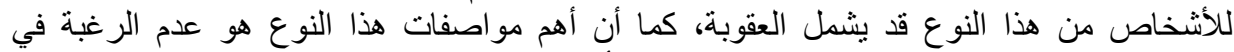

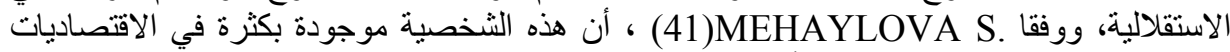

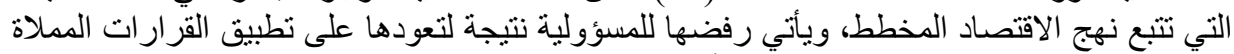

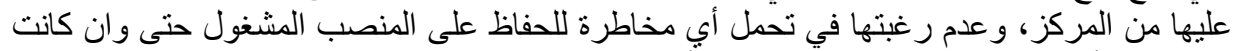

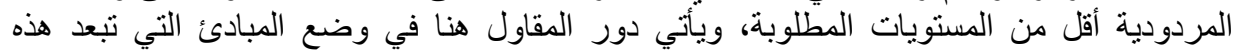

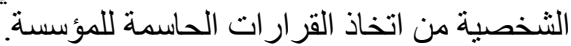
النوع Y: يطبق هذا النوع من الرقابة على الثخصية التي تلميز بالرغبة فئة في العمل، وتو افق أهدافه مع

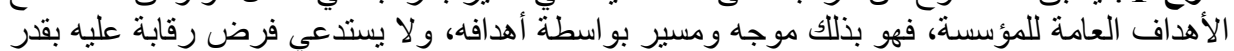

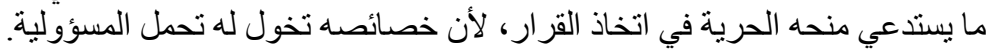

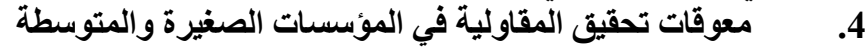

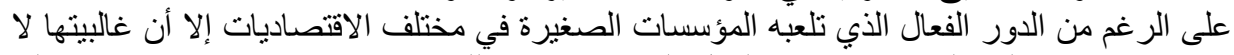

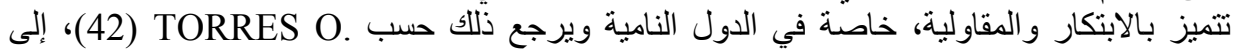

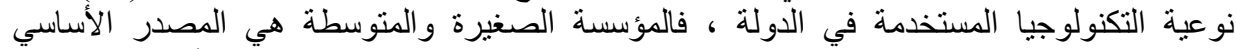

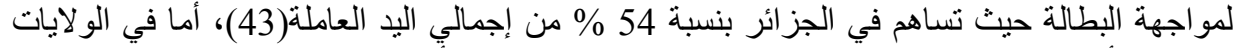

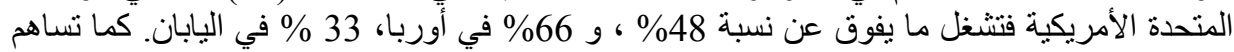

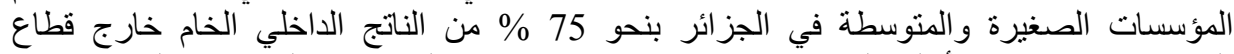

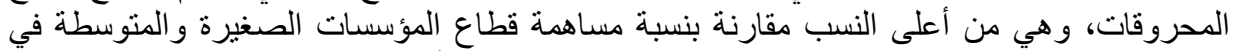

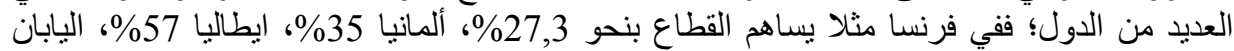

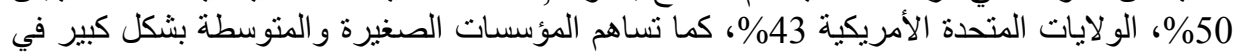

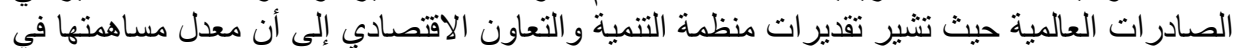

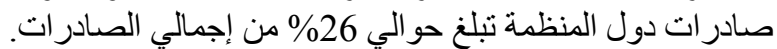
انطلاقا من هذا المنظور الدال على الدور الفعال الذّال الذي يؤديه قطاع المؤسيسات الصغيرة و المنتوسطة، سنحاول في هذا الإطار إبر از أهم العو ائق التي تقف وراء ضعف لأل مقاوليتها:

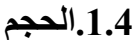

يعتبر الحجم وفقا لـ Desreuneu (1992) أهم عامل مؤثر من الناحية التنظيمية على المؤسسة، وهذا

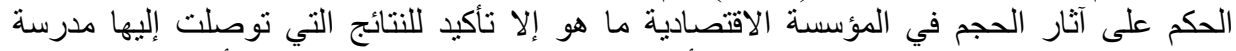
ASTON

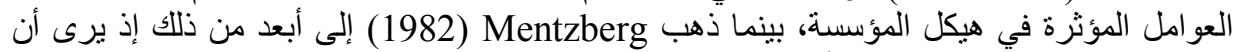

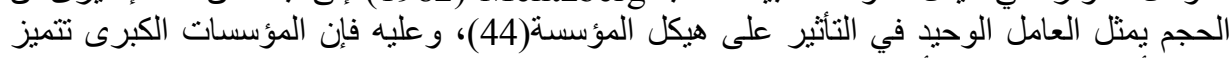

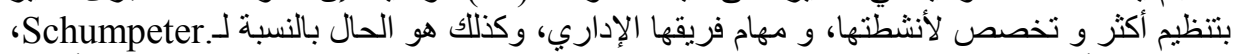
حيث يرى أن المقاولية تتحقق فقط في المؤسسات الكبيرة نظر الما لتحمله من تكاليف على الأبحاث

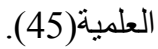

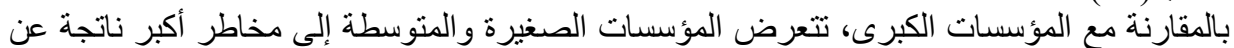

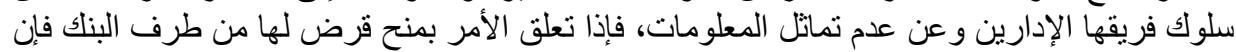

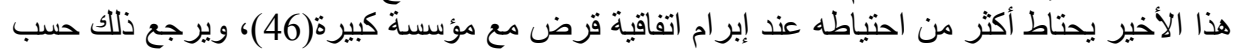
MAUSE

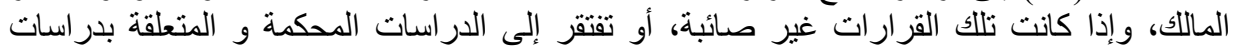

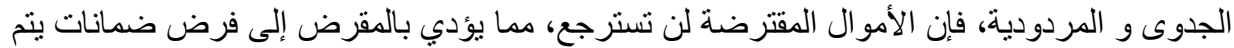

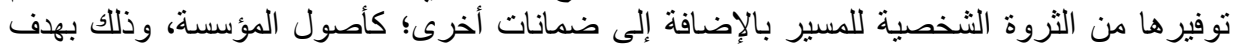


تعويض الخطر المتعلق بعدم قدرة المؤسسة على الوفاء بقيمة القرض، ومن هنا نلاحظ أن فرص المخاطرة و الاستفادة من الظروف تلكون اكبر بالنسبة للمؤسسات الكبئة الكبيرة.

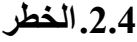

يعتبر الخطر دالة في تطور المؤسسة، أي أنه يزداد حسب كل مرلكة مرحلة من مراحل دورة حياة

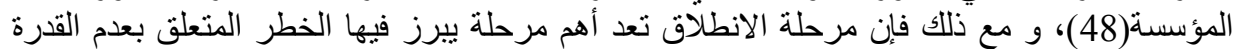

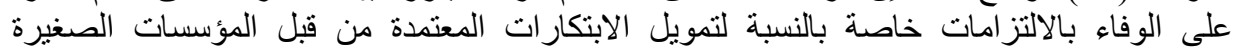

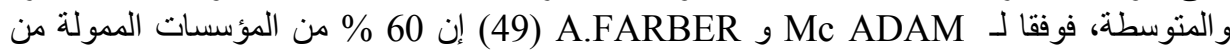

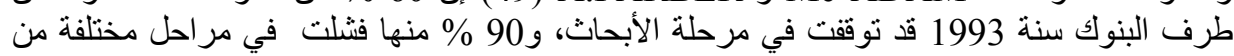

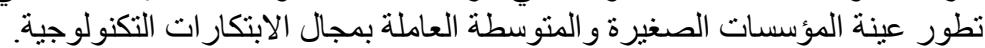

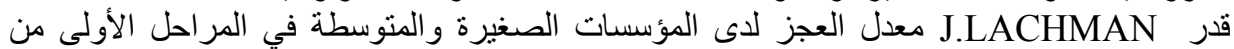

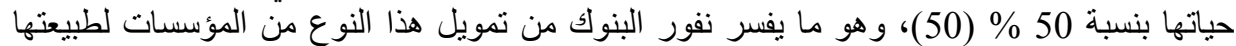
الخاصة تجاه الخطر و العجز.

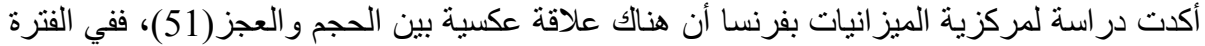

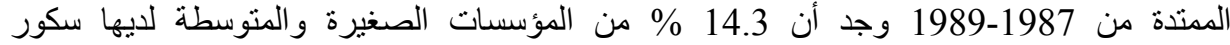
Z (SCORE) غير مقبول، بينما وجد أن 11 \% فقط من المؤسسات الكبيرة كان لديها سكور غير لان

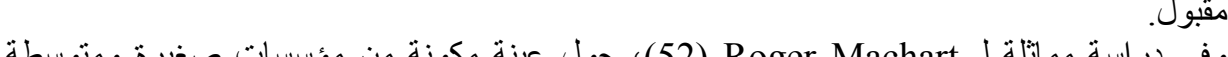

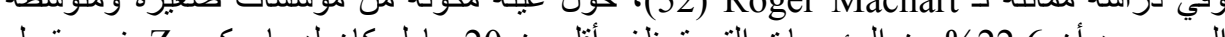

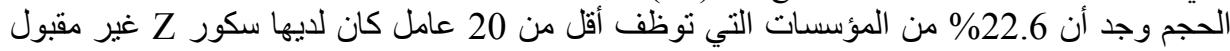

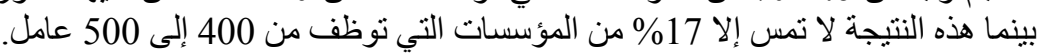
شكل رقم 1: معدل العجز في المؤسسات الصغيرة والكتوسطة سنة (فرنسا)

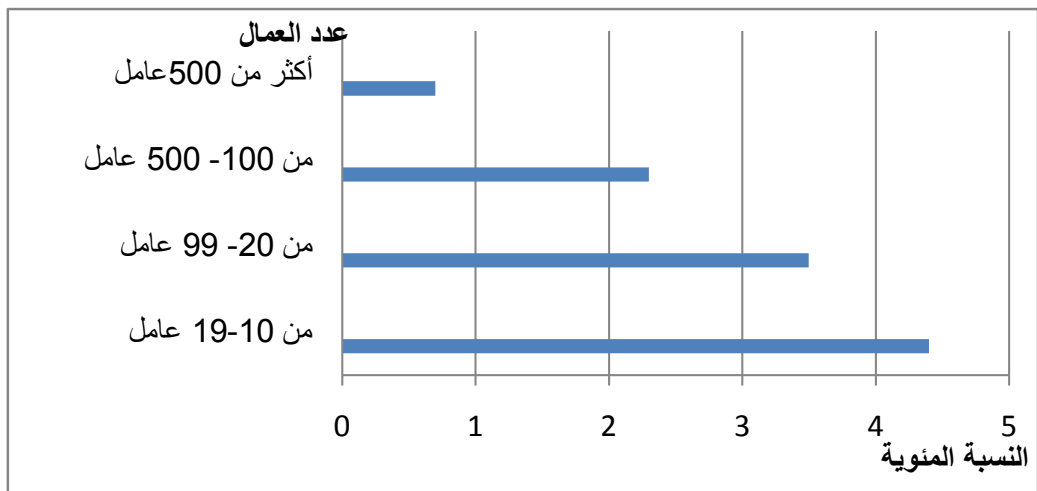

Source :PSILAKI M., op cit, p75.

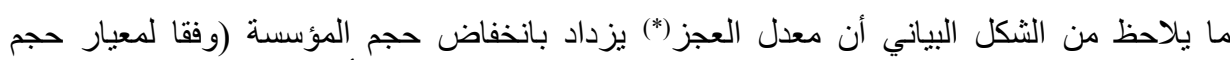

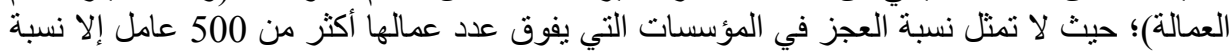

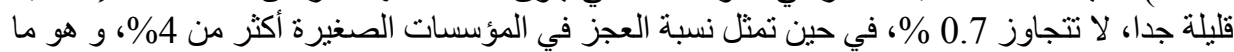

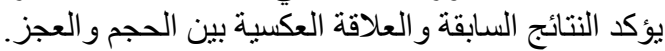

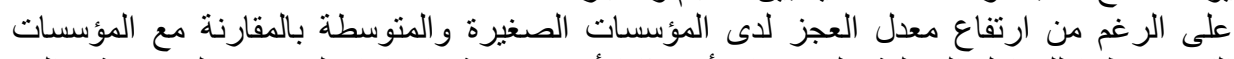

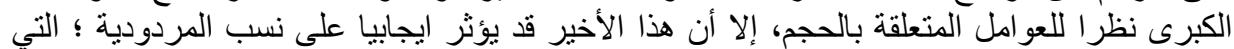

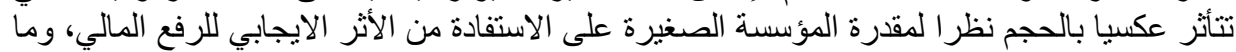


يضعف من فترة حياتها برجع إلى عدم قدرتها على التحكم في المصاريف المالية بسبب كثرة الاستدانة

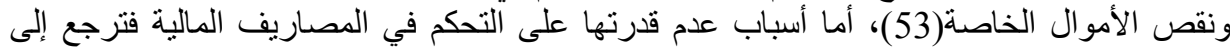

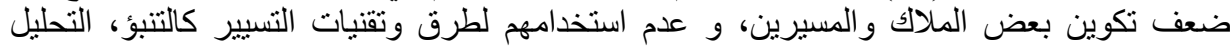

$$
\text { 3.4. }
$$

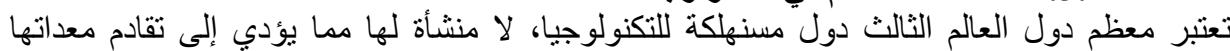

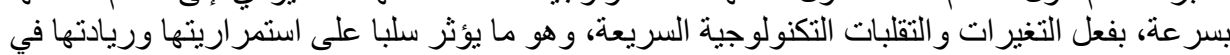

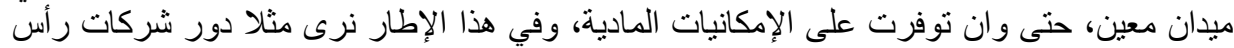

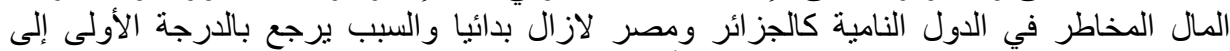

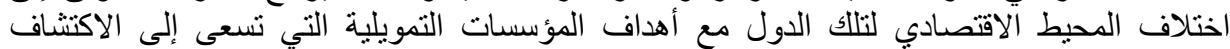

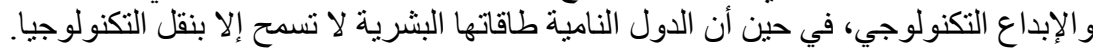

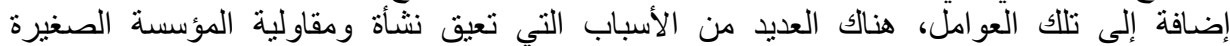

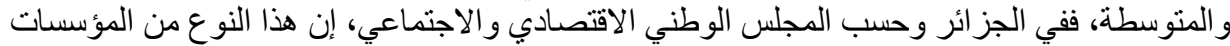

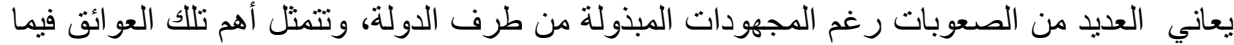
يلي(54): اليعاني

ـ مشكلة العقار الصناعي الناتجة عن عدم تنظيم آليات الحصول على العقار الصناعي و الحالة السيئة

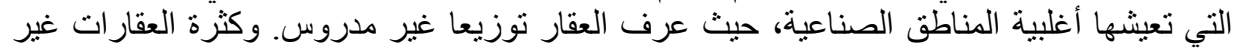

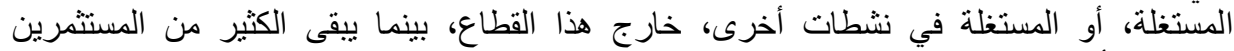

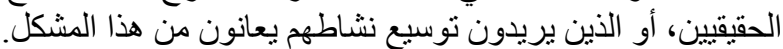

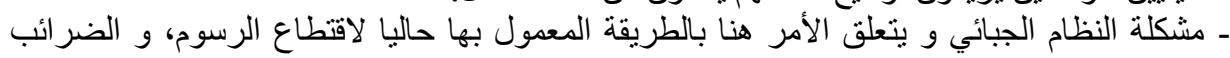

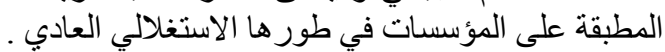

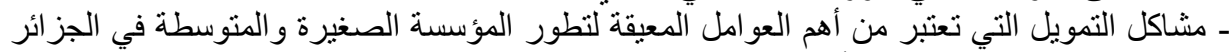

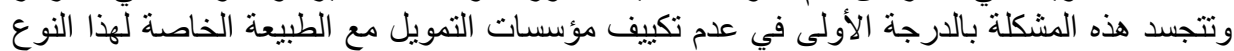

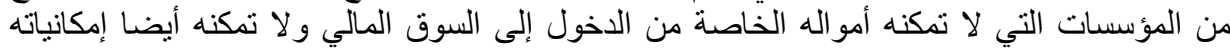

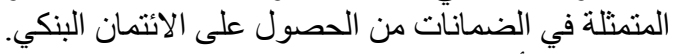

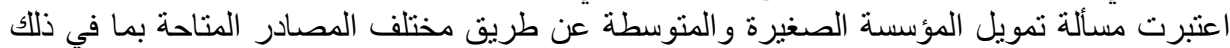

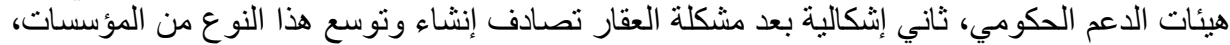
بينما يصنفها البنك العالمي في المرتبة الأولى من بين المشاكل التي تعيق الاستثمار في الجز ائر(55)،

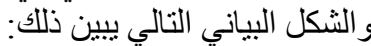
شكل رقم2: العشرة معوقات الأولى للاستثمار في الجزائر(بالمائة):

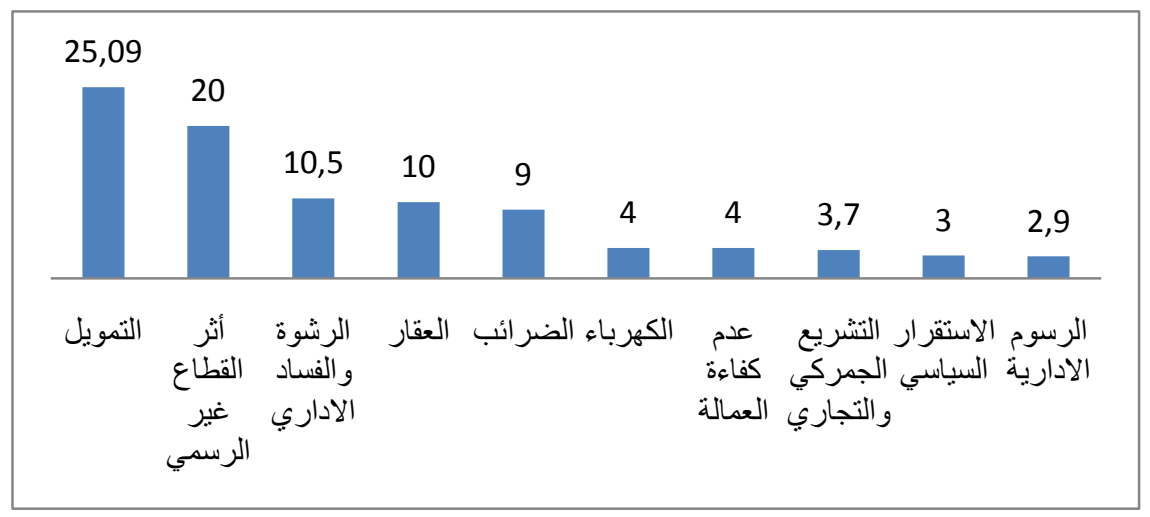


المصدر : تقرير البنك العالمي 2010، أنظر موقع الواب:

http://rru.worldbank.org/BESnapshots/Algeria/default.aspx

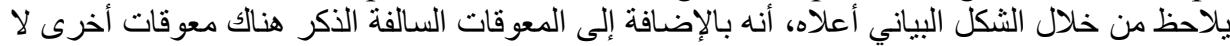

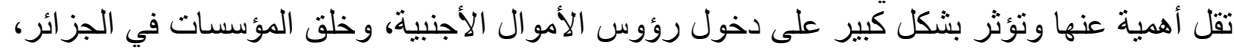

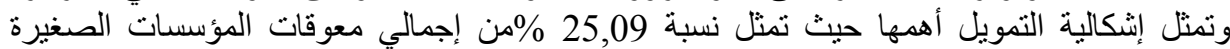
و المتوسطة، حيث صنفت الجزائر في جوان 2010 من قبل البنكانك العالمي في المرتبة 138 من حيث قدرنها على تلبية طلبات المقترضين.

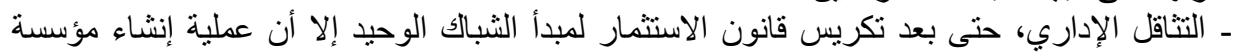

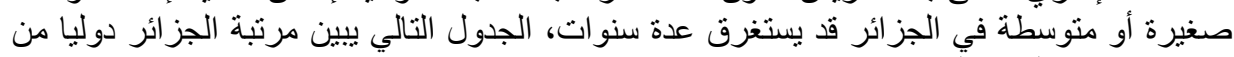

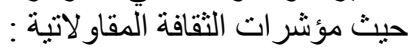

جدول رقم2: رتبة الجز ائر دوليا من حيث مؤشرات الثرات المقاولية في سنة 2010:

\begin{tabular}{|c|c|c|c|}
\hline المؤشر & المرتبة & المؤشر & المرتبة \\
\hline تسديد الضر ائب & 168 & إنشاء المؤسسات & 150 \\
\hline تتفيذ العقود & 127 & منح رخص الإنشاء & 113 \\
\hline حماية الاستثمار & 74 & تحويل الملكية & 165 \\
\hline & & الحصول على الائتمان & 138 \\
\hline
\end{tabular}

Source: World Bank, doing business 2011, Algeria, making a difference for entrepreneurs, comparing business regulation N 183, Washington, 2010, p2.

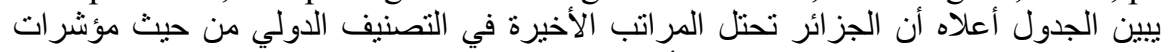

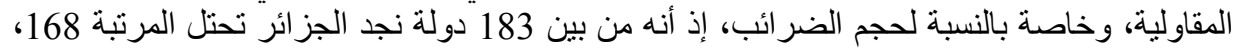

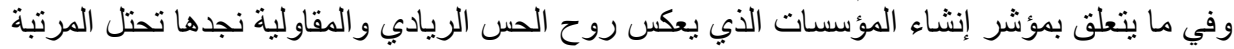

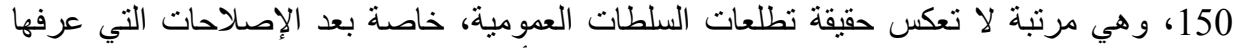

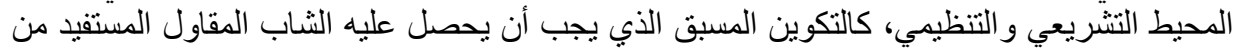
الدعم المالي الحكومي، وتعزيز دور صناديق الضمان.

خاتمة:

من خلال ما سبق نخلص إلى القول أن المقاولية رغم اعتبارها من أندر الخصائص البشرية، إلا أنه الثها

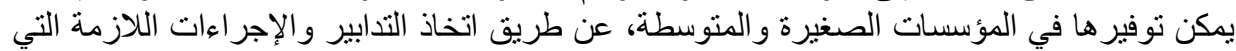
تمكن من تعزيز الثقة بالنفس، والتحلي بروح الميرة المبادرة ، وتدابير أخرى تهدف إلى تدريب وتكوين

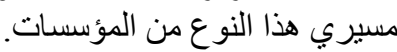

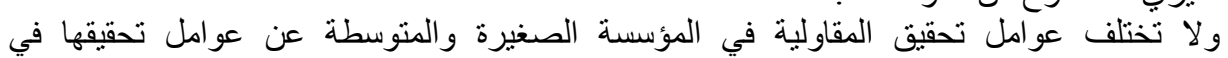

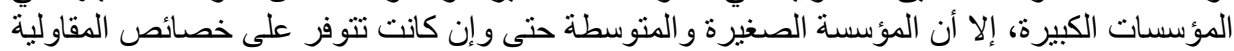

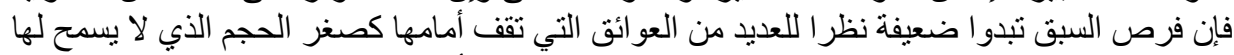

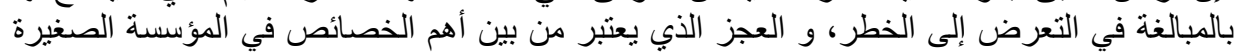

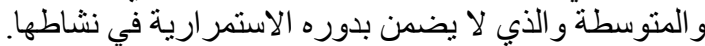

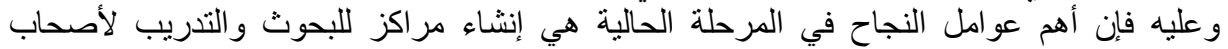

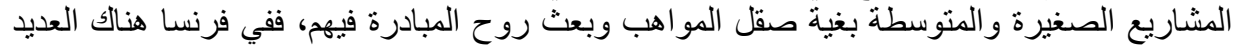

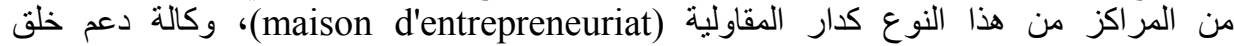

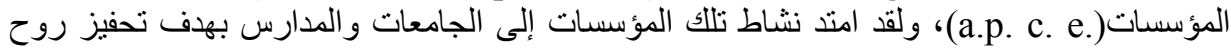
المقاولة لدى الثباب قبل توجها إلى الحياة العطلية. ومن خلال هذا المنظور الأخير يمكن إيجاز أهم التوصيات في النقاط التالية: 
تعزيز الدعم الحكومي للمؤسسات الصغيرة و المتوسطة، للوقوف أمام المشاكل و العر اقيل

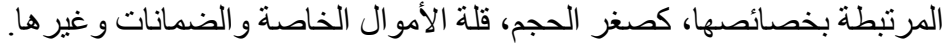

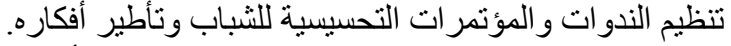

فتح التخصصات الجامعية و إنشاء مر اكز البحث حول تأطير الأفكار وتطوير ها.

1. MARY J.M., théorie des organisations: de l'intérêt de perspectives multiples, deboek, Bruxelles, 1971, P19.

2. LIVIAN Y. F., organisation théories et pratiques, dunod, paris, 1998 , P13.

3. COHEN E., dictionnaire de gestion, LA DECOUVERTE, Paris, 2000, P120.

4. MONTOUSSE M., sciences économiques et sociales, BREAL, Paris, 2004, p 110.

5. BOUBA OLGA O., l'économie de l'entreprise, édition du seuil, collection points, 2003, P9.

6. J. Peyrelevade, Économie de l'entreprise, Fayard, Paris, 1989, p. 10.

7. BENOIT F., Les nouvelles Logiques de l'entreprise, Cahiers français $n^{\circ}$ 309, Entreprises et entrepreneurs, p 21.

8. CHARREAUX G., PITOL-BELIN J. P., le conseil d'administration, Vuibert, 1990, pp12-13.

9. BORMANS C., L'indispensable de la pensée économique, STUDYRAMA, 2003, p113.

10. FAMA E.F., Agency Problems and the Theory of the Firm, Journal of Political Economy, Vol. 88, n², 1980,P290.

11. BENOIT F.,op cit, p21.

12. LIVIAN Y. F., op cit, p 14.

13. HEERTJE A., PIERETTI P., BARTHELEMY P., principes d'économie politique, De Boeck Université, 2003, p 349.

14. LIVIAN Y. F., op cit, p 14.

15. ULGEN F., la dynamique de financement de l'innovation, de boeck université, innovations N25/1, 2007,p 45.

16. AUBERT N., le leadership dans le management, aspect humains et organisationnels, P.U.F., 1991, p 372.

17. ALLALI B., vision des dirigeants et internationalisation des PME, PUBLIBOOK, 2005, p87.

18. IBIDEM.

19. DAFT R. L., Management, 4th edition, 1996, p 494.

20. COLLERETTE P. ROY M., Pouvoir, leadership et autorité dans les organisations, PUQ, 1991, p157-158.

21. DUCHENEAU B., les dirigeants de pme, chiffres analyses, pour mieux les connaître, Editions Maxima, 1996, P139: 
22. FORTIN P.A., devenez entrepreneur pour un Québec plus entrepreneurial, presses universitaire Laval, 1992, P65.

23. COGGIA v., intelligence économique et prise de décision dans les pme: le défi de l'adaptation des procèdes d'intelligence économique aux particularités culturelles des petites entreprises .HARMATTAN, 2009, p 30-31.

24. LEBRUN M.D., Regard sur la flexibilité des ressources humaines :une approche exploratoire systémique de la flexibilité, appliquée aux entreprises aérospatiales, 16e Conférence de l'AGRH - Paris Dauphine -15 et 16 septembre 2005, p3 .

25. HITT M., Keats B., De Marie S., Navigating in the new competitive landscape : Building strategic flexibility and competitive advantage in the 21 st century, Academy of Management Executive, vol. 12, $\mathrm{n}^{\circ}$ 4,1998, p34.

26. Fayolle Alain, Entrepreneuriat Apprendre à Entreprendre, Dunod, 1ere édition, Paris, 2004, p30

27. ALLALI B., vision des dirigeants et internationalisation des PME, PUBLIBOOK, 2005, p87.

28. IBIDEM

29. DAFT R. L., Management, 4th edition, 1996, p 494.

30. LEBRUN M.D., Regard sur la flexibilité des ressources humaines :une approche exploratoire systémique de la flexibilité, appliquée aux entreprises aérospatiales, 16e Conférence de l'AGRH - Paris Dauphine -15 et 16 septembre 2005 , p3.

31. HITT M., KEATS B.,OP CIT,p34.

32. ULRICH H., L'évaluation et le financement des start-up Internet, Revue économique - vol. 52, numéro hors série, octobre 2001,p 307.

33. BELLETANTE B., LEVRATTO N., PARANQUE B., diversité économique et modes de financement des PME, L'HARMATTAN, 2001, p321.

34. DUCHENEAU B., OP CIT,p 154.

35. LECERF M.,les petites et moyennes entreprises a la mondialisation, thèse de doctorat UNIVERSITE DE PARIS I -PANTHEON SORBONNE,PARIS, Janvier 2006, p 68.

36. DUCHENEAU B.,OP CIT , P 153.

37. IBIDEM.

38. FLAMHOLTZ E., growing pains, jossey bass inc. publishers, San Francisco, 1990,p 344.

39. DECHENEAUT B., OP CIT, P 151.

40. PONSON B., SCHAAN J.L., L'esprit d'entreprise: aspects managériaux dans le monde francophone; John Libbey Eurotext, 1993,p172. 
41. MEHAYLOVA S., le difficile apprentissage de l'autonomie de gestion, revue problèmes économiques, N 2701,21 fevrier,2001, p 11.

42. TORRES O., les pme, éd Flammarion, Collection Dominos, 1999,p4.

43. www.ons.dz/-statistiques-de-2001-a-2007-.html

44. TORRES O., pour une approche contingente de la spécificité de la PME, revue internationale des PME, Vol 10, №2, 1997, p13.

45. SCHUMPETER J.,capitalisme, socialisme et démocratie, PAYOT, PARIS, 1951,p195.

46. WTTERWOULGHE R., la PME une entreprise humaine, De Boeck université, Bruxelles, 1998,p135.

47. IBIDEM.

48. MICHEL A. P., COLOT V., vers une théorie financière adaptée aux PME, réflexion sur une science en genèse, revue internationale des pme, Vol 8, N³-4, 1995, p153.

49. Mc ADAM FARBER A., le financement de l'innovation technologique, GESTION, P.U.F.,1994, p25.

50. LACHMAN J., financer l'innovation des pme, ECONOMICA,1996, p 19.

51. PSILAKI M., rationnement de crédit et PME, une tentative de mise en relation, revue internationale des pme, Vol 8, $\mathrm{N}^{\circ} 3-4,1995, \mathrm{p} 74$.

52. IDEM, $\mathrm{p} 74$.

53. IDEM, $\mathrm{p} 71$.

54. www.cnes.dz

55. http://rru.worldbank.org/BESnapshots/Algeria/default.aspx

56. World bank, doing business 2011, Algeria, making a difference for entrepreneurs, comparing business regulation N 183, Washington, 2010, p36.

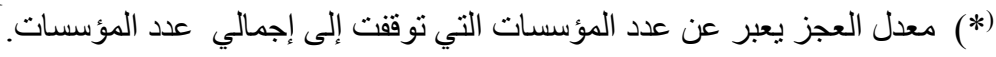

